\title{
Uneven anthology raises confidentiality issues
}

\author{
Pulse: voices from the heart of medicine: \\ the first year \\ Paul Gross, Diane Guernsey, editors \\ Change in Healthcare Publishing; 2010.
}

$\mathrm{T}$ he evidence-based medicine movement, with its emphasis on science, has been accompanied by a growing grassroots movement among both health care providers and patients to bring the affective narrative back into health professionals' education and practice. Courses, conferences and teaching tools have sprung up for doctors, nurses, their allied health colleagues and students. Some of these teach narrative and writing skills aimed at improving patient interactions and outcomes, while others promote selfreflection and offer outlets for processing the often-difficult experience of caring for the sick. Support groups for patients that include reading and writing personal narratives have also emerged.

This move toward narrative has inspired an array of anthologies. Some of these are compilations of works of literature relevant to medicine, chosen both for content and for literary merit, which are often used in more formal courses and to promote reflection. Other anthologies focus on patient, trainee and/or provider narratives. Although narrative anthologies often contain some excellent writing, their quality can be more uneven, particularly as the stories and poems therein may be chosen to provide authentic representation of a theme rather than for literary excellence.

Pulse: Voices from the Heart of Medicine: The First Year is a new offering from this latter group of anthologies. It includes stories and poems by doctors, medical trainees, nurses, a smattering of other health care professionals, patients and caregivers. All of these narratives were originally published in Pulse's online format (www.pulsemagazine.org) and in a free, weekly online magazine.

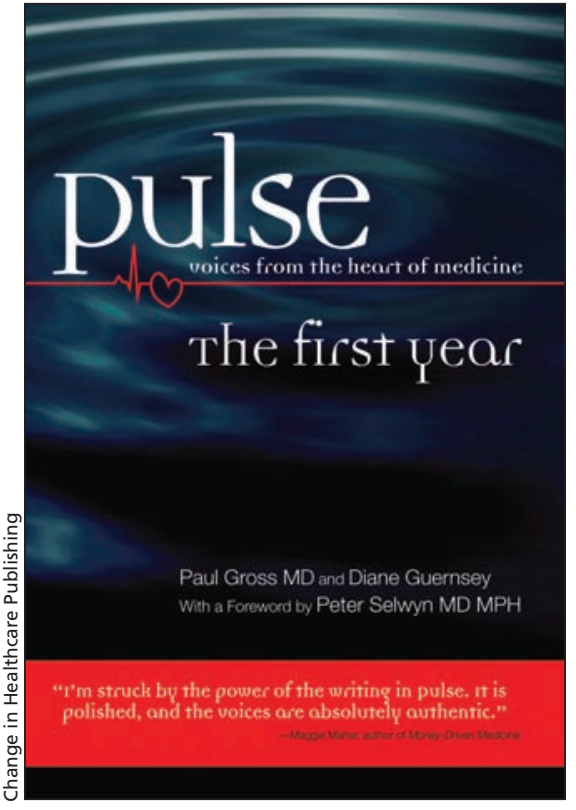

Each week's offering contains a single story or poem, and all of these offerings from the first year of this process (2008 to 2009) have been gathered and presented chronologically in this book.

Given the variety of voices and formats and the lack of an organizing principle related to either of these or to the contents of the narratives, it is not surprising that reading this book can feel somewhat jarring. Themes, authors and subjects appear, disappear, and reappear at random. The quality is also erratic, with some excellent stories and poems, like Lisa DeTora's See One, Do One, Teach One and Jimmy Moss's Little Black Boy, interspersed with decidedly mediocre writing. Each of these pieces on its own might have been judged good enough by Pulse's Editorial Board to arrive in subscribers' inboxes; juxtaposed in a single volume, their variability becomes much more obvious and disappointing.

What the narratives in this book do all have in common, however, is that they recount actual events that occurred in health care settings. The ethics of writing about such interactions can be problematic, and the onus is on authors, editors and publishers to ensure that confidentiality is respected. Unfortunately, this issue is not addressed anywhere in this book. The Pulse website does currently indicate that authors should "ideally obtain written permission from any patient you write about; as an alternative, you must change his or her name and omit or alter other identifying characteristics. A reader should not be able to pinpoint a neighbour, friend or family member as the subject of your writing." Health care professionals always have a responsibility to protect the privacy of their patients, no matter what the circumstances, and this policy does not seem very strong, particularly as it is unclear how it could be enforced.

However, Pulse's policy only relates to patient confidentiality, while many of its narratives are about health care workers. What about their right to privacy? Some of these narratives might identify individuals without their knowledge or even against their will. One could argue that if too much is changed to protect the privacy of every person mentioned in a story or poem, at some point it stops being the very thing Pulse aims to publish: a true narrative of the health care experience. Yet the need for this narrative voice in medicine and medical education can't justify betraying trusts and breaking confidentiality. What a patient, caregiver or provider may think of as his or her personal experience often involves a multitude of other people, each with a unique perspective and a stake in the story. Addressing this sort of dilemma requires thoughtful consideration by both authors and editors, and this book would have been significantly enriched by evidence of engagement with such a process.

\section{Ayelet Kuper MD DPhil \\ Department of Medicine \\ University of Toronto \\ Toronto, Ont.}

CMAJ 2011. DOI:10.1503/cmaj.101560 